\title{
Innovation Management and Barriers - Creating Space for Innovation and Organizational Change
}

\author{
Róbert Modranský ${ }^{a}$, Silvia Jakabová ${ }^{\text {b* }}$, Albert Oláh ${ }^{\mathrm{b}}$ \\ ${ }^{a}$ Prešov University in Prešov, Department of Managerial Psychology, Konštantínova ul. 16, 08001 Prešov, Slovakia \\ ${ }^{b}$ DTI University, Department of Didactics of Specialized Subjects, Sládkovičova 553/20, 01841 Dubnica nad Váhom, Slovakia
}

\begin{abstract}
The major purpose of this paper is to determine the opportunities and challenges relating to successful innovation management in SMEs in German and Slovakia. The objective and the subjective stances to research comprise three interlinking philosophies: epistemology, ontology and axiology. For this study the major design elements are the explanatory and the exploratory approaches and a case study is the selected research strategy. In order to answer the research problem, numerical and textual data is gathered. The empirical research studies revealed significant cultural influence on innovation management and related organisational change associated with it. It also highlighted substantial differences between success and failure factors in SMEs and large companies and there were implications that formal innovation management was less important from SMEs than for large companies. This research identified key innovation management success factors for SMEs and made three new findings, which add to the current knowledge: innovation circles were an effective innovation management approach to generating and developing ideas and getting innovation to market quickly; government agencies that encourage firms to collaborate effectively enhance the level and success of innovation; SMEs and large companies have distinctly different rankings of barriers to innovation and small and micro firms are more effective in original product innovation and speed to market than medium sized companies.
\end{abstract}

\section{Keywords:}

Innovation;

Organizational Change;

SME;

Barriers.

\section{Article History:}

Received: 04 June 2020

Accepted: $07 \quad$ September 2020

Published: $01 \quad$ October 2020

\section{1- Introduction}

Businesses thrive in a dynamic environment and in the contemporary global marketplace, organisations aim to survive by gaining competitive edge to increase their market share. As competition becomes increasingly difficult, companies need to find new ways of differentiating themselves, the traditional ways of doing business are becoming less attractive, because technology is constantly changing, and companies cannot must rely on their current positions. Whilst large companies become more rigid, smaller organisations gain market share because of their ability to innovate and adapt to new technologies, new market situations and customer needs [1]. The introduction of new technologies with appropriate strategies may also generate sustainable competitive advantage, this is not merely a consequence of adapting to change but also the ability to innovate. Large companies tend to react more slowly to changes in the market owing to their size and relatively bureaucratic structure, but they possess the resources to increase innovation. In terms of innovation, companies of all sizes experience advantages and disadvantages and traditionally innovation has been driven by a company's Research and Development (R\&D) department but many companies have recognised its limitations and implemented interventions that would expand their knowledge sources. Therefore, closed innovation represented by internal $R \& D$ is becoming obsolete and organisational preference is for an open innovation framework.

\section{*CONTACT: Jakabova.dti@ centrum.cz \\ DOI: http://dx.doi.org/10.28991/esj-2020-01236}

(C) 2020 by the authors. Licensee ESJ, Italy. This is an open access article under the terms and conditions of the Creative Commons Attribution (CC-BY) license (https://creativecommons.org/licenses/by/4.0/). 
The prerequisites for future success include the creation of the optimum environment for innovation so that competitiveness is continuously strengthened but often the challenges are the coordination of innovation specialists and removing organisational obstacles, such as silos, traditional sector mindsets, and bureaucratic processes. In contrast to large organisations, Small and Medium sized Enterprises (SMEs) rarely have an innovation strategy or an innovation management system for systematically planning and implementing innovative practices, partly because management is usually focused on operational activities that are necessary for survival, so that strategic considerations are relatively neglected.

Innovation research to date, for example Abulrub et al. (2012), Usman and Vanhaverbeke (2017) and Brem and Voigt (2009) [2-4], have focused primarily on large enterprises, rather than SMEs and therefore the purpose of this paper is to gain insight into the characteristics of innovation management including the challenges encountered.

\section{2- Material and Methods}

The major purpose of this paper is to determine the opportunities and challenges relating to successful innovation management in SMEs in German and Slovakia.

The resolution of this research problem requires a philosophy that enables integration of objective facts and subjective opinions, because cause and effect links between innovation management methodology and new innovation product or service success is usually measured by economic means. This economic measurement is based on numerical factors, for instance number of successful innovations and associated revenue streams. However, the selection of the appropriate innovation methodology is subjective, and relies on the company owner's preferences and cultural norms, as identified in the Literature Review bellow. Therefore, the research philosophy selected is a pragmatic approach [5]. The objective and the subjective stances to research comprise three interlinking philosophies:

- Epistemology;

- Ontology;

- Axiology.

Epistemology defines the types of knowledge that are considered as acceptable knowledge, whereas ontology describes different views of the world as perceived by individuals, in other words what reality looks like and axiology is associated with the values underlying the research. The key features of each type of philosophical stance and their inferences for research design and all the methodology associated with a research studies are summarised in table 1.

Therefore, the perspective of the pluralist philosophy is choice, the researcher adopts the stance most suitable for the specific research [5]. Since objective and subjective stances must be combined, the research design must reflect this, so for this study the major design elements are the explanatory and the exploratory approaches.

Table 1. Summary of Research Design and Philosophical Stances [6, 7].

\begin{tabular}{|c|c|c|}
\hline Assumptions & Objective Stance & Subjective Stance \\
\hline Epistemology & $\begin{array}{l}\text { Acceptable knowledge comes from one source } \\
\text { which can be measured }\end{array}$ & $\begin{array}{l}\text { Acceptable knowledge is constructed by human } \\
\text { beings and dependent on their life experiences }\end{array}$ \\
\hline Ontology & $\begin{array}{l}\text { Research object is independent of the social } \\
\text { actors such as observers or researchers }\end{array}$ & $\begin{array}{l}\text { Multiple perspectives of reality and social actors } \\
\text { and phenomenon are not separate }\end{array}$ \\
\hline Axiology & $\begin{array}{l}\text { Research is value free, since researcher has } \\
\text { not impact on phenomenon }\end{array}$ & Research is value laden \\
\hline Methodology & $\begin{array}{l}\text { Statistics are employed to measure the } \\
\text { phenomenon in an objective manner }\end{array}$ & $\begin{array}{l}\text { Interpretation of words and phrases expressed } \\
\text { about the meaning of the phenomenon }\end{array}$ \\
\hline Validity & $\begin{array}{l}\text { Certainty: data measures reality in an } \\
\text { objective,, accurate manner }\end{array}$ & Authenticity, credibility \\
\hline Reliability & $\begin{array}{l}\text { Research results can be reproduced by others } \\
\text { using same research methods }\end{array}$ & Confirmability and consistency \\
\hline
\end{tabular}

The purpose of explanatory design is to identify cause and effect links between key variables, in this case innovation management and commercial success, whereas the exploratory approach seeks to gain deeper insight into new phenomena or those that are not fully understood, as is the case with innovation management in SMEs.

The explanatory approach is highly structured, the researcher cannot deviate from a defined method and it relies on deductions that is matching the findings to existing theory. In contrast the exploratory approach is very flexible meaning that the researcher can explore unexpected findings freely and with the purpose of attempting to discover new theory [8]. 
In this paper a case study is the selected research strategy because it focuses on a small number of SME companies, in which real life issues are experienced and its purpose is to use multiple sources to gain deep understanding of innovation management within them. The case study is ideal for this research because it answers questions of what, when, how and why so that different perspectives on the issues can be expressed. Hence the case study forms the unit of analysis for the research [9]. The data gathering, and analysis is conducted using mixed methods, because the method is well established with the pragmatic philosophy and allows the objective or positivist approach to be employed concurrently with the subjective stance [9]; it also provides a more holistic understanding of the issues so that the answer to the research problem demonstrates more than one perspective [10].

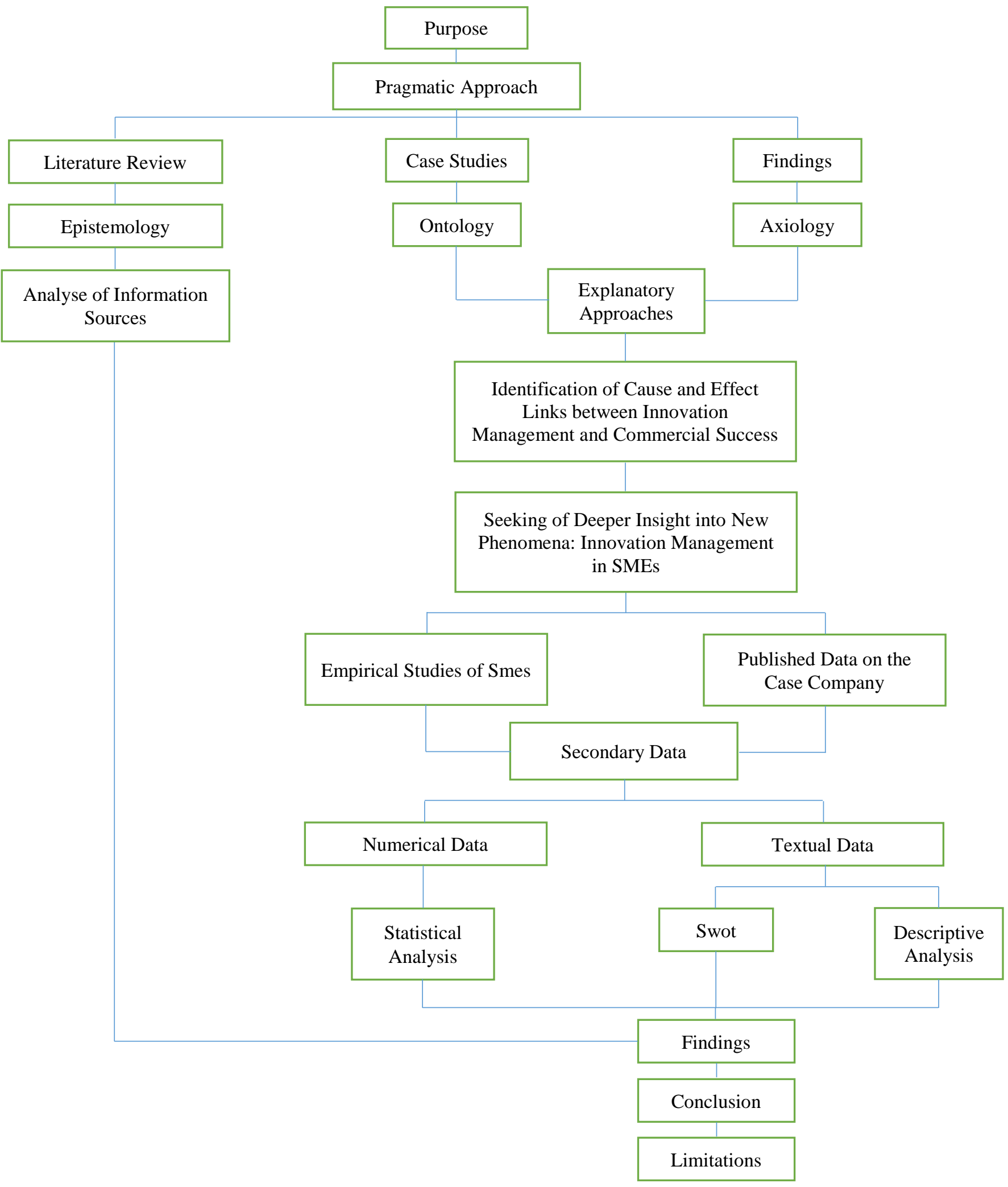

Figure 1. Methodology Scheme. 
In this research secondary data is gathered predominantly from empirical studies on SMEs and published data on the case company; since these data sources are permanent the research can be repeated easily and therefore the reliability of the findings is enhanced [11]. In order to answer the research problem, numerical and textual data is gathered but it is analysed in different ways. The numerical data is subjected to statistical analysis, which means that statistical constants indicate the significance of the findings, in other words is there a proven relationship between the two variable or not. The textual data is scrutinised to find recurring themes, expressed in the publications in certain words and phrases. Each of the themes is interpreted by the research with the purpose of expressing the meaning that the author associated with the words in the text.

The appropriate methodology is employed to enhance the reliability and validity of the findings. In terms of reliability the researcher provides full details of all research sources so that another researcher can access all of the data sources, whereas the validity of the findings is demonstrated by the degree of convergence they have with previous studies, for instance. There are not participants in this study, since secondary data is the only source, hence the major ethical consideration is to ensure that the original author's intentions are expressed when interpreting the data [12].

\section{3- Literature Review}

Innovation is required for sustainable business but is a complex process that is often accompanied by organisational change, but change management usually fails [13], because the challenges of implementing change are as problematic as accomplishing successful innovation. Therefore, identifying a robust strategic change management system is vital.

\section{3-1- Definition}

Organisational change management is difficult to define, since the term managing change has two distinct inferences: making changes in response to impacts over which the organisation has little control; invoking change in a planned and systematic manner [14]. Contemporary organisations are confronted with diverse challenges resulting from globalisation and technological advances, which have necessitated new forms of operation and control.

A broader definition of organisational change suggests that globalisation is "an increasing consciousness of the organisation of finance, investment, production, distribution and marketing in ways that pertain to or embrace the world; a phenomenon that has both reinforced and been reinforced by the wider, more longstanding but continuing noting that history of technological developments that have reduced the significance of geographic space" [14]. Globalisation has invoked diverse business risks for enterprise organisations, so that they must implement improvements to maintain competitive stance and to survive; in other words, change processes are vital to the retention of competitive advantage. These processes vary according to the organisation's characteristics, and may include elements of structure, vision and culture, financial aspects, organisational locations and control, transformational relationships, and technological developments. Therefore, organisational change management can be primarily described as the implementation of efficient, effective methods to foster modifications throughout the organisation, whilst simultaneously encouraging all employees to accept the change, which is the most challenging aspect. Sustaining change is very challenging, as most companies comprise multiple work cultures which make change management increasingly difficult [16]; sustainable change requires changes in organisational behaviours, values and rituals.

The importance of change management and the high failure factor, are reflected in the academic interest in the phenomenon, for instance [14], subdivided it into four cycles, which describe the content and levels of change, means and processes, episodes and phases, and sequences and patterns of change. In comparison, Alvesson and Sveningsson (2016) assume that the most important factors are its dimensions, sources, content and the political aspect. Therefore, it is apparent that both economic and social factors change an organisation, so that management planning is vital and that change cannot be effected by spontaneous experiments conducted by subordinate managers and employees [15].

Change may be instigated in various ways, from the need to resolve internal issues to engaging technological advances and strategic change must be shaped in terms of its scope, resource use, synergy and competitive advantage. This means that strategic change is the change of the goals and vision of an organisation by focusing on achieving greater success; changes implemented do not always succeed. The reasons for failure include poor implementation that is often characterised by poor communicate of change to the employees, and most importantly resistance to change because the organisational culture is so deeply embedded, according to Naghibi and Baban (2011) [8].

\section{3-1-1- Culture}

The advantage of a pioneering, innovative company is associated with the leaders' capability to create an organisation that continuously learns to adapt to the changes external environment [18]. The creation of a culture that is open to new ideas is vital for managing innovation, stimulating employee creativity to enhance the company's 
innovation capability [17]. Organisational Culture comprises values and beliefs that generate certain behaviours, which when embedded represent a barrier to change because it has developed over time and often reflects the original founder's values [20]. The shaping of organisational culture is one of the core leadership tasks, and therefore if change is to be sustainable all employees must be fully involved in the process so that behaviours alter to those appropriate to the current and future organisational environment [18]. This social learning process must be directed by leadership which shows visible commitment to the change, social competence and perseverance [21].

\section{3-1-2- Change Management}

Change is associated with new policies, behaviours, patterns, methodologies, products or new market ideas and the management of change involves the design and construction of new patterns, or the re-conceptualisation of old ones, so as to enable more productive activities [20]. Change may also include the transformation of structures, procedures, regulations and rules, technology, education, and development [21], affecting all parts of an organisation [20]. However, organisations are mostly affected by environmental changes, which require an adjustment of inner processes to influence employees reshape their values and behaviours so that they coincide with selected strategic direction [22, 23 ] argues that the workforce is the main facilitator of change, because they are involved into the processes of change and Swedberg and Douglas (2003) [24] propose that gradual implementation limits resistance to change. Therefore, change can be understood as an ongoing process that occurs in public and private organisations and enables organisations to compete and develop innovative products or skills more effectively and generate higher profits and/or other desired goals. However, if change is not effectively managed there will be not change, and the organisation is unlikely to survive in the longer term goals [25].

\section{3-1-3- Organisational Change Models}

The design of a successful change process is based on knowledge of the expected outcomes and must focus on development of employees to embrace the new characteristics of the organisation to accomplish this goal [26].

One of the most employed models for effecting long term successful change was developed by Mullins (2010) [27], which focused on leadership for change process suggesting and eight stage process. As a precursor to any organisational change, an analysis of the external environment is vital and accomplished most effectively by establishing which factors represent opportunities and threats to the organisation and how it can shape its resources to manage them to drive competitive advantage. Therefore, first stage in the process is to create a sense of urgency, if the management and employee are too complacent, possibly as a result of current or past successes, they will not be interested in driving change. Urgency can be developed by interventions such as highlighting the levels of customer dissatisfaction or poor sales figures by circulating data to more individuals or providing them with information regarding the future opportunities that have been identified in the environmental analysis; visible crises gain management and employee attention.

The second stage in the change process is to form a leadership coalition, which refers to: identifying a group of key organisational stakeholders with the power to implement the changes and to support them so that they are able to collaborate effectively. The members of the coalition are focused on the future direction of the organisation, have sufficient experience and credibility, and capable of developing common goals and building trust. However, individuals to be avoided in the coalition are those with inflated egos and self-interest and other that create mistrust and hinder effective teamwork.

Develop a vision of the future shape of the organisation, which relies on innovative leaderships skills, and a transformational leadership approach is the third stage; the leader sets the direction and influences other to participate by means of constructive collaboration developing a shared vision, which then allows generation of the related strategy.

Stage four is communicating the vision of change to the entire organisation and making sure that each individual is included by employing all traditional and virtual communication methods, for instance workshops, presentations, newsletters, emails, corporate intranet, notice boards. The leader also demonstrates visible commitment to the change, for instance by his/her changed behaviour that aligns with future requirements. The variety of media, the repetition of messages and the time devoted to discussion and debate enables employees to questions concepts, contribute ideas and to observe changed behaviours in the guiding coalition team.

The empowering of employees to contribute to eliminating barriers to change, by suggesting changes to systems or structures that would hinder accomplishment of the vision, for instance departmental silos, lack of skills to implement new technologies for the benefit of the customer. Encouraging new ideas, behaviours and activities that support vision and strategy and exchanging them with leadership so that training can be shaped and organised and human resource systems align with the vision, such that managers who oppose change are not able to negatively affect employee enthusiasm and impede change [28]. 
Achieving and celebrating short term goals, referred to as short term wins, which are genuinely related to the change goals, visible to many and unambiguous, for instance realising the cost savings that were targeted or shortening product development time by a third.

Stage seven is to consolidate what has been achieved so far to enable further change for instance all systems, structures, and rules that are inconsistent and do not align with accomplishing the vision. In the stage new employees are recruited, existing employees that have the competences to continue to achieve the designated goals are promoted and new projects are initiated. Change agents are selected to support those who are finding change difficult, instigating two way conversations with them and shaping change as merely a new way of completing tasks, as well as creating an understanding that change is continuous. Visible leadership is required at all levels as well as project management and identifying and eliminating obsolete internal processes which have been traditional, for instance monthly report from one department to another.

The last stage referred to as anchoring approaches in the culture, this is a vital stage if real cultural change is to occur because all of the previous steps integrated new processes and practices but may not have altered the deeply held organisational cultural values; Kotter (2012) [28] stresses that cultural change is the last intervention and can be extremely difficult.

Hence, suggested modes of altering the culture include increasing performance by a strong focus on delivering customer value and other behaviours that increase productivity. When the successful outcomes from defined goals become apparent employees are most likely to embrace them. Leaders at every level will need to generate continuous dialogue with their teams regarding how to perfect new practices, providing support and encouragement, especially to those who fine new methodology difficult to implement. In addition, leaders must realise the inevitability of staff attrition as some employees are likely to reject change. Equally those individuals who have contributed most to enabling the changes should be recognised and at all levels, for instance by promotion or other appropriate reward [28].

The eight stages represent a long term change plan, not a quick fix and Kotter (2012) [28] stresses that most change strategies fail because leaders begin at stage five and fail to involve the whole organisation from the time when the need for change is recognised. The first four stages are vital to reducing the status quo, the habit and traditions that represented the organisational norms [25].

\section{3-1-4- Barriers to Organisational Change}

The challenges to successfully implementing organisational change directly impact on innovation capacity because the new culture is one that fosters innovation and referred to as an innovation culture. A range of internal and external barriers exist to accomplishing an innovation culture, for instance internal bureaucracy and external social acceptance of a new technology.

In term of internal barriers to cultural change, organisations should identify what actions they could take to improve the innovation process and the speed to market, these two aspects are the most significant challenges, according to Porras and Robertson (1992) [13]; inadequate innovation culture hinders the release of creativity potential possessed by employees. A poor innovation culture is typified by organisations, which fail to allocate suitable resources, have bureaucratic decision making processes and are risk averse regarding new projects; innovation culture impacts on potential for creativity in companies of all sizes, but is most prevalent in large, established organisations [13]. Large companies tend to rely on a high degree of division of labour, a hierarchical structure and defined process, which impede spontaneous creativity and organisational learning [29]. Since organisational leaders are responsible for shaping corporate culture, their leadership objectives determine whether driving innovation is considered vital [30] Leadership approaches, which do not include foreseeing the future shape of the organisation, will also stifle internal entrepreneurship and networks to exchange intelligence and comprises human resource systems that preserve the status quo [13]. An additional barrier to organisational change to develop an innovative culture is short term orientation, which eliminates the practice of systematically searching for original, disruptive innovations; this short term mind-set is common in many western organisations, which have processes to measure and report monthly or even daily earnings, associated incentive schemes and high management turnover [13]. Small firms may also fail to focus on disruptive innovation because their survival depends on customer orientated product development to generate revenues in the short term [13].

When a firm generates a large number of innovation projects, the high cost and the time lost in determining which have the most potential for commercialisation and ultimate market success presents a barrier. Concentrating on a small number of projects that have been systematically selected for their success potential in terms of new customer value, not only optimises human and physical resource use but encourages shared responsibility for accomplishing the R\&D objectives including speed to market [13]. 
Market launch processes for new products are a major barrier and, whilst the company's size is not a major factor, the industry segment is relevant. The division of labour and very long development periods often lead to loss of opportunity, which has been more rapidly exploited by domestic or foreign competitors. The technical focus on the new product may also hinder its commercial value as changing customer preferences have not been the major driver of innovation [13].

The main external barriers to changing to and innovation culture are regulation, bureaucracy, social acceptance, accessing employees with the requisite skills and knowledge, the external environment including sourcing the funding. The inhibitory effect of regulatory frameworks and bureaucratic procedures are exemplified by strict occupational safety, environmental and consumer protection regulations, which consume resources that could be applied to innovation. The bureaucracy and regulation relating to new technologies deters SMEs from innovating to produced them [13].

The barrier that relates to social acceptance often poorly understood [31], it is very often linked to regulatory requirements, but the early adopter stage of the product life cycle is characterised by small numbers of consumer purchasers, who know about the product and are willing to take the risk that it will accomplish the claims made for it. This success of this stage is vital to more general acceptance as more information emerges.

Skills shortages are major barrier to innovation, especially professional skills especially in science and technology but also the soft skills required for collaborative working and information exchange and intercultural competence [32]. The location of SMEs may also present a barrier to accessing graduate and postgraduate students, who tend to prefer major cities in which larger established firms are located. Large companies also have more resources to recruit staff on a global basis, although they may be somewhat hindered by immigration restrictions [13].

A major barrier to innovation for SMEs is attracting adequate funding for new projects, owing to lack of collateral to act as security for a loan or absence of company credit rating [13]. The projects that tend to be favoured by funding organisations such a venture capitalist are high tech innovations rather than application related research. Access to suitable funding sources with terms and conditions that are manageable by SMEs is one of the major enablers or restrictors of developing an innovation culture and instigating the associated change management initiatives.

\section{4- Findings and Discussion}

\section{4-1- Empirical Research on Innovation Management in SMEs}

The published studies on SMEs tend to be very sparse compared to those focusing on innovation and change management, and therefore this paper provides the opportunity to evaluate research conducted in a range of countries, in respect to the established theories and concepts. This research, discussion and analysis represents a series of case studies from previous research can be compared with the German case study that is presented in chapter five.

\section{4-1-1- Innovation Management in Selected European Countries}

A relatively early study on innovation management, focusing on management of technology related to technological innovation, and compared the practices of SMEs headquartered in the United Kingdom (UK), France and Portugal. A questionnaire survey was developed in collaboration between researchers based in each of the countries and sent to executives working in SMEs, which specialised in manufacturing, transport, communications and construction. The 233 SMEs participating represented $25 \%$ of those contacted and, which returned completed: 68 from UK, 77 from France and 88 from Portugal. Quantitative methods were used to analyse the responses, SPSS and linear regression analysis [33].

The respondents from all countries agreed that innovation was driven by changes in the external environment, which necessitated organisational changes of behaviour in order to become more innovative, in order to retain competitive advantage in their sector. In relation to a successful recent innovation, participants rated thirteen factors for accomplishing it in order of importance; the most important factor were expressed as customer demands, customer relationships and detailed analysis of competitor products and services. However, difference emphasis was placed on these in the three countries, in UK and Portugal customer demands a competitor analysis took precedence over customer relationships as a source success than French firms, whilst French and UK firms the contribution of customer relationships to be more influential than Portuguese SMEs.

Portuguese and UK SMEs considered that formal and informal external contacts were a high contributor to success, whilst French firms relied far more on internal R\&D. Overall the executives' satisfaction level with the SME's innovation behaviour was highest when it had been instigated by client demand. The sources of information gathering in French SMEs were considered much more important than in either UK or Portugal, focusing on a wide range from, external R\&D sources such as universities, to suppliers, Chambers of Commerce and equipment vendors. The proportion of sales revenues allocated to R\&D was lowest for Portugal, explained by its preference for external $\mathrm{R} \& \mathrm{D}$ support. 
Overall the amount spend on external R\&D was not found to correlate with innovation success. In addition, innovation performance was negatively correlated with financing networking activities with institutions such as Chambers of Commerce as it had little impact on innovation performance [33].

Significant differences regarding the influence of working relationships and processes on innovation success was found, for instance the Portuguese relied most strongly benchmarking against best practices and employment of internal quality improvement groups. External sources for improving innovation processes were rated most highly by the Portuguese in terms of employee training and accessing consultants and working with competitors.

The French also emphasised the high impact of internal quality improvement groups on innovation, whilst rating IT as having less effect. UK firms by comparison took a very broad view of processes and working relationships influencing innovation success, rating all options almost equally: key suppliers, customer and external consultancy received the highest scores, but these were 20\% lower than Portuguese and 10\% lower than French scores [33], suggesting less conviction relating to any small group of factors.

Hence the French were most focused on internal relationships and processes and Portuguese on external relationships and processes as innovation success support factors. However, the high value of close working relationship with major customers was agreed by executives in all countries, as well as the relative value of cross functional team working that was most preferred by Portuguese managers. Innovation satisfaction was most associated with the external pressure for continuous improvement and with technology management, with factors such as R\&D expenditure and internal processes being statistically insignificant. However, emphasis on the two factor varied, for instance the French being less focused on continuous improvement and highly concerned with technology management, the Portuguese adopting the opposite emphasis.

Whilst UK managers focused more on continuous improvement, sector technological innovativeness and structures for managing technology were more highly valued [33]. These national/regional differences suggest that local conditions, organisational cultures, and perceptions of the level of technological importance are the underlying reasons for them.

The relative potential for innovation success by companies, which had an internal R\&D focus and those which employed innovation management was the purpose of a study by Rammer et al. (2009) [34]. This research relied on data relating to innovation in German SMEs, submitted to the European Union (EU) Community Innovation Survey (CIS) on an annual basis but is particularly useful because the German survey contains many additional, noncompulsory insights into SME innovation environment. Since the same sample of companies is surveyed each year, with new SMEs added only when part of the sample is no longer active, many more questions regarding innovation activities, market environment and economic performance, plus it includes very small firms with five to nine employees and a much bigger proportion to service companies. The breadth of participants, which all have less than 250 employees, is useful to answering the research question underpinning this research and the quality of data employed is also highly robust suggesting that the findings of the study are supportive to this research.

The number of innovating firms for which there is complete data in the period 2000 to 2002 was 1049 of a total of 2841 SMEs [34], suggesting that less than one third of German SMEs focus on innovation activities. The innovation success (SUC) of an SME was judged in terms of market novelties, product line novelties, efficiency innovation and quality innovation and for firms, which had accomplished positive economic performance, either regarding sales revenues, sales growth or cost savings.

Nine variables relating to R\&D aligned with the questions comprising the CIS questionnaire, with the four SUC success factors employed as the basis for sections of the questionnaire, Table 2. The nine HRM tools are those most often used to generate innovation, for instance, identifying individual to drive innovation and promoting them of the basis of outputs, training and developing skilled employees, Use of innovation circles, and shared decision making. The eight teamwork tools incorporated open communication, sharing development of innovation strategy, changing the specialist composition of project groups on a temporary basis and mutual support to resolve innovation problems [34].

Table 2. Description of the Nine Variables Relating to R\&D [34].

\begin{tabular}{ll}
\hline \multicolumn{1}{c}{ Name } & \multicolumn{1}{c}{ Description } \\
\hline Innovation success & $\begin{array}{l}\text { Number of different types of innovation: market, product line, efficiency, quality generating quantitative } \\
\text { innovation success in } 2002\end{array}$ \\
Permanent R\&D & In house R\&D conducted from 2000 to 2002 \\
External R\&D & External R\&D conducted 2000 to 2002 \\
Permanent \& External R\&D & In house and external R\&D conducted from 2000 to 2002 \\
$\begin{array}{l}\text { Human Resource Management } \\
\text { (HRM) }\end{array}$ & At least one of ten HRM tools was very important to support internal innovation activities from 200 to \\
& 2002
\end{tabular}


Teamwork

External Source Search

Cooperation agreements with external partners
At least one out of eight team working or cross functional tools was very important to support internal innovation activities from 200 to 2002

Any of the external sources invoked product or process innovation from 2000 to 2002: suppliers, customers, competitors, universities, other public research organisations

Products or processes from 2000 to 2002 that were developed by collaborating with external firms or collaborative contracts in force at this type

Firm Size

The main findings of the study were that innovation success was most reliant on continuous R\&D activity, particularly when external $R \& D$ sources were employed but that even firms, which did not use them and had no R\&D in house expertise could be successful by devising an appropriate strategy.

The irregular use of external $R \& D$, for instance to resolve a specific problem was not an indicator for innovation success. Is to create innovation success tools, including human resource practice that support innovation, for instance selective recruitment, skills and teamwork development. These strategic actions taken as an integrated approach can lead to innovation can be strengthened further by accessing external knowledge or formal collaboration.

The findings also suggested that the potential success of complex innovation activity would be enhanced for non R\&D firms by developing internal technology competence and then exploiting it by outsourcing it and learning from the external user; higher performance at lower risk.

Therefore, the findings from this study emphasise the importance of innovation management for innovation success related to organisational change, in terms of developing effective strategy and aligning this with an HRM function that promotes and supports cross functional team work, employee recruitment and training that acquires and develops the necessary skills. If the organisation has an in-house R\&D function this can only be most effective as an innovator by also sourcing external knowledge [34].

A study of Irish SMEs sought to identify how innovation was managed in New Product Development (NPD), in other words, to establish its contribution to innovation success. This research was considered important because less than $40 \%$ of Irish firms were described as innovative, and yet Ireland was rated $9^{\text {th }}$ in the European Union as a result of CIS; the contribution of SMEs to this rating was uncertain. In addition, firms involved in NPD were characterised by extremely poor staff retention but employed more staff. Large companies and foreign owned organisation were twice as likely to be innovative than Irish firms in NPD and process innovation. Hence the findings of this study, contribute to this research in terms of SMEs innovation activity in a culture that has a weak innovation reputation and whose innovation management activities appear to be somewhat unique in terms of the national output [35].

The data on the selected Irish SME firms was gathered in Innovation Week in Ireland in 2010 by means of a convenience sample and on the basis of that relating to the stages of the innovation value chain, the formal stages in NPD, by using an online tool developed for the purpose. Whilst 596 firms self-selected to participate in the research only 173 of the completed audits were usable. This was because the firms needed to comply with the scope of the study as Irish firms, with less than 250 employees, whether they had introduced an original or significantly altered product or service in the past three years, and stated whether their innovation effort was formally managed or not. The participating companies comprised $44 \%$ with less than 10 employees, micro firms, $39 \%$ classed as small businesses with 10 to 49 employees and 17\% medium sized firms with a workforce between 50 and 249 .

The innovation value chain was perceived as comprising three stages: generation of the idea, its conversion towards a commercial propositions and diffusion in which the whole organisation became involved. Idea generation generally occurred within a unit of the firm, an individual or group, was then shared internally with others and might then be shared and discussed with outside partners. At this stage, the Key Performance Indicators (KPIs) relating to each of these idea generation group stages would be matter of the number of high quality ideas were generated by initial groups, collaboration groups and outside contacts, were all of some of them most innovation idea generation productive. Conversion was characterised by two stages, selection and development with KPIs for selection reflecting the effectiveness of the screening and subsequent funding processes for innovative ideas by the percentage of original ideas that are selected and funded. Development KPIS are associated with the firms' capacity to commercialise the selected ideas into feasible products aligned with the relevant business processes and good practices. The KPI measures the percentage of those funded ideas, which generate revenues within a specified time frame. In the third stage of the value chain, KPIs focus on diffusion through the organisation, innovation effectiveness is measured according to the percentage penetration in the SME's selected markets, marketing channels, groups of customers until full diffusion has occurred. Two hypotheses were tested in the study [35].

H1: A formal process for managing innovation is associated with higher innovation performance in terms of revenue generated by new products and services and then the originality of the new products and services 
H2: A formal innovation management process is associated with superior performance at each stage of the innovation value chain

The survey responses revealed that $23 \%$ of participants had a formal innovation process and managed innovation in a distinct way compared with those innovating in an informal manner. This formal innovation process comprised $79 \%$ developing a specific innovation strategy, $72 \%$ developing KPIs to measure progress in the innovation process, $83 \%$ creating specific teams to drive the innovation idea to commercialisation, $67 \%$ appointed an official team leader and $59 \%$ created a formal innovation budget for each project. In contrast the informal innovation firms were characterised by just $10 \%$ creating a strategy, $17 \%$ creating formal KPIs, $16 \%$ with a budget but $55 \%$ had instigated dedicated teams. The reliability of the data is confirmed, as these aspects were found to be statistically significant with $\mathrm{p}$ values much less than $\mathrm{p}<0.05$, mostly $\mathrm{p}=0.000$.

Overall innovation performance measured on the basis of commercial success and whether the innovation was the first of its genre to be marketed; the findings revealed that $38 \%$ of all firms had generated significant proportions of their total revenues from innovation products and 31\% claimed that their innovation was first to market [36]. These findings are particularly interesting since they reveal that less than one quarter of Irish SMEs have a formal innovation management process, but it also reveals the key components of that process: a defined strategy, development of formal metrics, appointing a responsible person for its accomplishment and a team of suitable employees as well as creating a separate R\&D budget. In the non-formal innovation management group, the use of such measures is low and sporadic, suggesting a few or none of these management techniques are ever used.

Comparison was made between the innovation outcomes of the $23 \%$ with formal innovation management and the remainder of the sample revealed the difference in innovation performance the resulted. The economic outcomes for firms with a formal innovation management process were that a high proportion of total revenues were generated from the innovative products and services, $47 \%$ on average over the previous three years, in contrast to 35\% for SMEs without formal management mechanism but the hypothesis $\mathrm{H} 1$ that formal management was responsible for the difference was not proven statistically at $\mathrm{p}<0.01$, the value obtained by $\mathrm{p}=0.029$.

Therefore, firm size and industrial sector activity, product or service activity, were tested for significance. The average proportion of total revenues from innovative products in the past three years was $39 \%$ for micro and small SMEs and $30.9 \%$ for medium sized organisations; new service firms generated $40 \%$ revenues and new product firms $35.5 \%$ on average. On this basis, the importance of the formality of the process was tested related to SME size and sector and the statistical analysis revealed that significantly higher revenues were generated by micro and small businesses in both the product and new service sectors because they had adopted a formal innovation management structure; $55 \%$ of total revenues over three years compared with an average of $38 \%$ total revenues for firms without a formal innovation process.

The originality of new products or services, being the first of its type of the market associated with the highest level of innovation capacity and willingness to take higher risks, was also associated more often with a formal innovation management process than with the informal innovation approach, $56 \%$ compared with $24 \%$. However, the difference in the proportion of originality between formal and non-formally managed innovation could not be statistically proven to be dependent on the SME size or product/service activity [35].

The presence of a formal innovation management strategy across the three stages of the innovation value chain was not proven to generally be a driver of any of the stages, but it did impact on three specific factors. In the conversion stage the higher risk taking attitude of firms towards original innovation ideas with a formal management process was statistically significant, $67 \%$ of firms compared with $38 \%$ of those lacking formal management. In the development stage of conversion the difference between the managed and non managed responses to managers being supported to develop new ideas was proven, the responses being $79 \%$ compared with $40 \%$. In the diffusion stage, the formal management process was statistically proven to account for higher penetration of new products across all customer groups, channels and regions; $39 \%$ of formally managed innovation companies failed to penetrate all groups compared to $66 \%$ wihout management formalities [35].

Whilst the hypotheses were not proven and no statistical difference was detected overall concerning superior performance generated by formal innovation management and non formal innovation processes, across all three innovation value cycle stages, in terms of product originality distinct differences were proven. In these Irish SMES, significantly higher numbers of original new products were generated, capacity for risk taking and being first to market were higher.

The lack of difference in the innovation value cycle outcomes when formal and informal management were employed was partly attributed to the small size of most Irish SMEs and the small number of projects that they developed at any time, which could allow the flexiblity required to successfully innovate in a non formal mode [32]. The overall conclusion of the study was that formal innovation management was associated with large firm innovation success and might not be of substantial importance to most SME situations [35]. 


\section{4-1-2- Open Innovation in Asian SMEs}

An investigation of open innovation was conducted by Moore (2004) [40] to establish how prevalent the practice was in Korean SMEs, with the rationale that open innovation had been first attributed a large firm status. The capacity of large firms to access resources and particularly technological resources, which they could share with other large firms was considered to be a driver that SMEs did not possess, despite the acknowledge ability of SMEs to generate and commercialise creative ideas [40]. Therefore, the research focused on identifying and appraising the extent of open innovation in Korean SMEs, presenting ideas of how it could be stimulated. Secondary data was obtained from a study by the Technology Innovation Survey STEP1 conducted in 2005, with the objective of gaining insight into Korean SMEs. The survey comprised investigation of the innovation activities of 2743 Korean firms between 2002 and 2004, of which 2414 were SMEs [33]. Eight categories of innovation management were identified so that comparison between large firms and SMEs could be achieved: specific training for innovation; marketing; gathering external knowledge; identifying and employing external R\&D; organisational change; support for product or process innovation; acquisition of machines or other facilities requiring capital investment. The degree to which each of these categories was uses by large companies and SMEs was calculated from the data, the findings are presented in Table 3.

Table 3. Comparison of Innovation Active Prevalence in Korean SMEs [40].

\begin{tabular}{lcc}
\hline Innovation Activity & Large Firm (\%) & SME (\%) \\
\hline Training for innovation & 84 & 63 \\
Innovation Marketing & 61 & 47 \\
Employment of External Knowledge & 67 & 53 \\
External R\&D Introduced & 50 & 46 \\
Organisational change & 78 & 67 \\
Product and Process Innovation Support & 75 & 68 \\
Internal R\&D innovation focus & 92 & 85 \\
Acquisition of new facilities and equipment & 78 & 73 \\
\hline
\end{tabular}

The initial observation from these findings is that, SME activity in most activities is much lower than that of large firms except for internal and externa $R \& D$ focus, acquisition of new capital equipment and organisational change, where the gap is quite low. SMEs also appear to be less interested in accessing external marketing information that might generate new ideas because it was not a priority given the lower people resource, and innovation training. Other reasons for the difference in effort between the two groups were found to be the type of innovation activity, whereas small firms focused on invention, development and commercialise pattern for original new products or services, large firms were most frequently employed in customising existing products or services for individual customer. Therefore, marketing to gain consumer interest in purchasing the SME invention was more difficult for SMEs because of their lack of marketing expertise, unless the innovation was intended for a specific customer, who would conduct the marketing function. In fact, both marketing approaches were used by SMEs and when the product/service was invented for a specific customer, the potential for successful market launch and sales revenues very much higher. Hence marketing activity and training to commercialise own innovate new technologies was identified as a major intervention required to ensure market acceptance [40].

The lower use of external information by SMES was evaluated according to its type and relevance compared with large firms. Internal information sources ranged from development to research, sales and marketing and purchase type, development and research being rated most important and by 77 and 69\% SMEs respectively. External information was gathered from three main sources; other firms and their market such that customer, competitors and affiliates were the most important information sources and employed by 59\%. 56\% and 315 firms respectively; universities government agencies and research centres were considered less relevant with $43 \%$ using university sources and 33\% government agencies as prime informants; publicly available information had the highest usage, over $70 \%$ of SMEs used the exhibitions and the internet and rated them the best sources of this type. However, the highest scores on information importance were customer/user, industry competitors and affiliates. The priority SMEs place on external information from these three sources is interesting as it implies that external sources and, therefore open innovation management, is a vital component of strategy for Korean SMEs. However, the data gathered on all types of externally generate information was quantitatively analysed in relation to the numbers of each of four types on innovation each firm had generated in the three years 2002 to 2004; major product innovation, minor product information, service innovation and process innovation. When the correlation between external information sources and innovation type was conducted the results showed that the first three correlated with depth and breadth of external information accessed at significance level 0.01 but that process innovation was not correlated to depth and breadth of external information. Whilst the depth of external information appears to have a little more impact on major than minor product innovation, it is the breadth of information that is more highly correlated to service innovation so that SMEs should focus more on customer needs from target markets by using the most important information sources [40]. 
The trends and impact of collaboration of the SMEs with external inormation sources, the universities and research centres and external firms and markets revealed that collaboration with other firms for technology purchasing was preferred more than developing strategic alliances, which was not a frequent type of SME relationship. Association with technology firms, particularly those in non-competing markets, provided access to new technologies required for their innovation development prociess without exposing its nature, lowering risk of the innovation being copied by a potential competitor. However, when strategic alliances were formed, the preference was greater for universities that other firms because fundamental long term research is considered necessary. The barriers to SME innovation by 817 firms were more active in forming strategic alliances were analysed, ranked and compared to those found by large firms, the score attributed to each barrier has a maximum value of five; summary is presented in Table 4.

Table 4. Barriers to Innovation in Large Firms and SMEs [40].

\begin{tabular}{|c|c|c|}
\hline Barrier & SME Ranking and Score & Large Firm Ranking and Score \\
\hline Shortage of skills in labour market & $1(3.12)$ & $3 \quad(3.00)$ \\
\hline Internal skills shortage & $2(3.10)$ & $11 \quad(2.71)$ \\
\hline Market uncertainty relating to innovative products & $3(3.00)$ & $18 \quad(2.20)$ \\
\hline Possibility of technology innovation imitation & $4 \quad(2.95)$ & $16 \quad(2.39)$ \\
\hline Limited R\&D planning and management resource & $5 \quad(2.91)$ & $23 \quad(1.75)$ \\
\hline Lack of technological information & $6 \quad(2.87)$ & $(2.79)$ \\
\hline Technology uncertainty in generating funding problems & $7 \quad(2.85)$ & $26 \quad(1.55)$ \\
\hline Funding problems owing to high innovation and commercialisation cost & $8 \quad(2.79)$ & $(3.06)$ \\
\hline Lack of market information & $9 \quad(2.78)$ & $(2.84)$ \\
\hline Staff turnover, usually R\&D staff & $10(2.66)$ & $(2.94)$ \\
\hline
\end{tabular}

Other lower ranking barriers for SMES included R\&D having low organisational influenced rated $16^{\text {th }}$ but $8^{\text {th }}$ for large companies, but the market structure as a monopoly or oligopoly was rated the highest barrier to innovation by large firms with a score of 3.16, whilst it was the lowest for SMEs. Non-payment for innovation was a high barrier to large firm innovation, ranked 4 with score of 2.96 compared with rank 25 by SMEs, scoring 1.97.

The SMEs relevant to this aspect of the study were categorised as: all SMEs; generating one innovation between 2002 and 2004; adopted one strategic alliance for innovation in the specific period. The analysis revealed that the most barriers to innovation were expressed by the last group, which were usually involved in technological innovation, perhaps providing a rationale for more innovation difficulties. From the perspective of this study the stark differences in the ranking of barriers suggests an extremely different environment for open innovation exists for SMEs compared with larger firms [40].

The last aspect of this intensive study was focused on the outcomes of an engineered collaboration process for SMEs operating in Korea, referred to as KICMS, established in 2004, in which specialist SMEs collaborate horizontally, temporary collaboration in cross functional collaborative families known as CF2s, so that each SME is responsible for one part of the innovation, selected on the basis of its competitive advantage; collaboration is contracted on the basis of mutual trust. The 4415 firms participating in KICMS by 2007 and the innovation factors regarding one of the networks set up by KICMS was investigated as an open innovation management model. The network consisted of five firms that formed the strategic alliance to commercialise antenna technology, and idea based on a flat satellite dish enabled by Wave Guide Horn, a transmitter of high frequency electronic energy

The technology was not well developed and only one Korean SME had the relevant technology that could be applied in a non-military environment but it had financing issues, such that the other four firms collaborated with the objective of generating high revenues from a potentially valuable product, marketing R\&D but with previous experience in satellite dish manufacturing, marketing distribution comprising export, import and agencies, telecommunication component wholesaler, electronics manufacturing and moulding manufacturing; marketing distribution representing over five times large number of employees than other firms. This collaboration generated significant change in the original firms' outcomes, specifically: total sales rose by 437\% to 7,752,00 Korean Won, costs decreased by $14 \%$, and productivity increased by between $10 \%$ and $20 \%$. The outcomes were attributed to innovation management by the firms, particularly relating to creating trust, effective information exchange and transfer of expertise.

In other CF2s that operating under KICMS, success was not the outcome, mainly as a consequence of inadequate financing despite the firms making a joint investment and government funding was suggested as being a priority to enhance economic innovations but based on the specific business case and potential success of the innovation rather than past SME history [33]. This study represents a major case for this research, because the data used is from reliable sources and employed comprehensively to appraise the impact of a variety of factors on open innovation management in SMEs. 


\section{4-2- Discussion}

The above cited studies on innovation management revealed a range of diverse but significant findings, which show distinct convergence with the major concepts and theories relating to innovation and organisational change. In all three studies, the impact of culture on the management of innovation, specifically, which aspects are considered to be important and the national reputation for innovation converge with idea the capacity of leaders to create an innovative culture in the organisation is of paramount importance [16]. They also highlight the difficulty that firms appear to have in altering their innovative attempts from that associated with national culture, generating the necessary organisational change, to appeal to a more global market for instance, traditionally the Irish SMEs have little innovative culture and fail to significantly contribute to the nation's high cultural standing in EU ratings [18], and less than 30\% German SMEs participate. The French appear to concentrate on internal R\&D and neglect external information available from customers, whereas the UK and Portuguese firms are more open to external contributions, with Portuguese being particularly externally focused. Hence, new patterns, behaviours and methodologies appear to change very slowly and learning is likely to be inhibited [20]. The Korean study also demonstrated that in terms of open innovation 50\% or less of large firms and SMEs considered interaction with the external environment important. Therefore, the relatively low commitment to the social learning process that drives change may inhibit SMEs from optimising the initiation of innovation and of competitive advantage it represents [18, 22].

Innovation management was considered to comprise scanning the external environment to identify change [41], changes in organisational behaviour to optimise innovation [42], but customer demands, customer relationships and detailed analysis of competitor products were cited as more important in the first cross cultural study. In the German SME study nine factors were identified, which added teamwork, HRM tools and collaboration with external contacts. An interesting innovation management activity that was only mentioned in this study was specific innovation development practices, for instance the creation of innovation circles, changing the specialist composition of project teams regularly and interventions to enable employees to share information to develop the innovation strategy. These activities reflect at the very least a type of innovation process is concerned [42] and in some cases a managed approach to change that mirrors the first four stages of Lajčin et al. (2017) [19] eight stage change model, however, in terms of actual innovation management the concept of innovation circles did not appear in any of the established innovation management literature in the Literature Review for this study and can be considered a new finding. It may also be particularly suitable for SMEs owing to the flexibility of their organisational structure. In the Irish study formal management procedures were not found to generate superior outcomes that when no formal innovation management took place, the higher outcomes shown by the data for innovation management could not be statistically linked to innovation management.

In the Korean case, eight categories of specific innovation management were identified: training, marketing, employment of external knowledge, introducing external R\&D, organisational change, product and process innovation support and internal R\&D focus. This conception of innovation management implies focus on strategic and operational issues as were mentioned in the German study in which appropriate strategy was considered to be a substitute for it, converging with [43].

In the Irish SME case a different type of innovation evaluation process was employed and concentrated on managing three distinct innovation stages, rather than focus on finer detail such as resources; attention to internal and external idea generation, development of the concept and then distribution of products into the relevant market [44]. Hence this approach was also highly concerned with marketing innovation [45] and organisational innovation [42]. The focus of this model is very similar to Dyer and Singh (1998) study [46].

However open innovation was considered in all four studies, and perceived be relatively unimportant in the early study which spanned three countries, especially in France, where the implication was that closed innovation was preferred [47]. The date of this study may have some relevance to the overall conclusion made by the researchers, since globalisation has generated more focus and diverse approaches as external environmental changes have increasingly impacted on firms [48]. The findings of the study of German SMEs the German study suggested that whilst combination of internal and external sources for innovation often provided a superior outcome, that this could be equally well achieved by a closed approach if the firm developed a suitable strategy, which has some alignment with the RBV concept of the firm [47]. The study also suggested the major open innovation choices was outside-in [16], as did the Irish SME study, which mentioned no knowledge sourcing activities except use of external knowledge.

As with the Irish SME prime activity and competence, the Korean firms tended to focus most, and most effectively on original new innovations, using the invention, develop and commercialise process. They also concentrated on both outside-in and inside-out, coupled open innovation [49], and with a wider range of contacts, since universities and research centres were also a preferred source, especially for long term projects and the lower risk of exploitation of their ideas by an external partner. This represents a different context for innovation that found in the other three studies, much broader external knowledge sourcing and possibly a consequence of governmental agency supports to extend networking in these firms; a factor not mentioned in the established literature and therefore a second new 
finding from this study. Hence, the findings from these studies align with the established theory, that identical innovation processes and approaches are to be expected owing to each firm's specific set of circumstances.

Innovation success factors varied from a need to use open innovation on a continuous basis if the firm opted for open innovation, otherwise success was less certain, to highly detailed innovation management as in the Korean case but also developing detailed strategy as a substitute for formal management, an idea that has similarities to the German eight element innovation management model. Social acceptance factors were emphasised by the Korean case, specifically the marketing activity and training required to ensure that the original invention met market needs; the Korean SME focus on customers, competitors in the same market and affiliates aligns with this strategy and with the established literature's emphasis on social acceptance as a success factor. The Irish case also suggested that managed innovation resulted in more original product and service innovations and faster market introduction and penetration; these findings tend to align with the Korean research. The importance of working closely with key customers was also mentioned in the cross cultural study, this align with altering behaviours and organisational change to leverage productivity [28]. Cross cultural team working was found to a success factor in all cited studies, but the Irish study also mentioned appointing a team manager, defining key metrics to measure progress, and specifying an R\&D budget [42].

The barriers to SME innovation had substantial emphasis in the Korean study, which rated them by impact finding that shortage of skills in the labour market and internally were the two highest barriers, followed by market uncertainty, new product or service imitation by competitors and limited R\&D planning and management. In the other studies the main barriers highlighted were lack of access to financing networks; many of these align with established studies. A third new finding emerged from the Korean study, which established a list of ratings of barrier to innovation for SMEs and large companies, and whilst the Irish study noted that formal innovation management appeared to be more important in the large company context than for SMEs. Whilst the highest barriers to innovation for SMEs related to skills shortages, market structure was rated first for large companies; large companies ranked labour market skills shortages 3 and internal skills shortages 11 .

A surprising finding from the Irish context was that large firms tended to be more innovative than SMEs, which is partly contradicted by the findings of that study, which show that the micro and small SMES have more capacity for getting original products to market and speedily, as well as generating higher proportions of their total revenue from them than medium sized companies. In the Literature large firms are considered to have lower innovation capacity than small firms, so that the findings of this study do not align with accepted theory that large firms are less innovation ready owing to lack of organisational flexibility. However, the Korean study also suggested large firms had advantages for innovation, specifically their access to advanced technologies that SMEs did not.

\section{4-3- Summary}

The five empirical research studies conducted in a range of nations, revealed significant cultural influence on innovation management and related organisational change associated with it. It also highlighted substantial differences between success and failure factors in SMEs and large companies and there were implications that formal innovation management was less important from SMEs than for large companies, because the smaller SMEs, in particular, had the flexibility to change direction relatively easily.

The authors came to similar conclusions in the context of the Czech Republic in article [36]. This article focuses on the concept of innovation management in SMEs, based on the fact that change management in a hypercompetitive environment is a decisive competitive advantage for small companies in comparison with big ones. The authors describe innovation management in terms of process management based on management plans and targets and their controlling. Innovation management is considered as system management of processes, products and strategic changes.

In Slovakia, this issue was addressed in Lendel et al. (2015) [37] research. The purpose of this research was following a detailed analysis of literature and realized research to create a model of innovation processes management in the company. In the solving of defined problem, the authors identified key innovation competencies (innovation expertise, information security, management and performance evaluation) and main difficulties of innovation process management in terms of Slovak companies (empirical research realized by authors). Valued results of this study are also formulated recommendations how to correctly manage innovation processes in a company. As a main conclusion can be mentioned: Management in company is important in the field of innovation processes management. A key assumption for the successful realization of the innovation processes is the existence of a supportive environment for innovation creation. For managers can be recommended to implement and use the system of self-evaluation of innovation processes in company [37].

Sulaiman et al. (2010) [38] thoroughly dealt with the issue of innovation management in the Asian environment. This study aimed to map the experience of the RIU Asia projects and drew out the main innovation management 
tactics being observed while laying the groundwork for further research on this topic. It provided a framework to help analyse the sorts of innovation management tasks that are becoming important. This framework distinguished four elements of innovation management: (i) Functions (ii) Actions (iii) Tools and (iv) Organisational Format. The paper's review of the distribution of innovation management in the Asia projects suggested that it is not technology accessrelated tasks alone that are important, but the bundling of these with other activities, which include the development of networks, advocacy for policy change, training and other negotiated changes in practice and action. The implication for policy was that ways of supporting this wider suite of innovation management tasks would go a long way in helping make better use of agricultural research in rural development. Similar conclusions were drawn by De Meyer and Garg (2004) study [39].

\section{5- Case Study}

In this section, a new case study is developed to provide insight into a Slovak SME and its innovation culture. The company overview is followed by an appraisal of innovation for change and recommendations for action, based the findings and relating to the concepts appraised in the Literature Review.

\section{5-1- Company Description}

The MVI Group was founded in 1988 by Julius Kiss as an engineering and consulting company, which supported the product development of large companies and now operates in the international automotive and mobility sector. The company literature states that it has developed a strategy that allows it operate with a flexible organisational approach so that is can adapt to changing markets and it has developed systems to ensure that new technical expertise and methodologies are integrated and constantly updated.

MVI Group has several divisions, for instance MVI Proplant, MVI Solve IT, MVI Automotive and MVI Promotive. MVI Proplant is involved in manufacturing and logistics projects that range from factory and production planning to resource development and to highly efficient production information systems. The largest MVI Proplant unit is MVI Proplant North, located in Wolfsburg and employing approximately 250 individuals, whilst MVI Proplant South is based in Munich with approximately 90 employees, and MVI Proplant Slovakia as 60 employees. This unit is analysed in presented paper. The organisation's history has impacted on each of these units in diverse ways, so that they are characterised by different operational tasks and associated challenges, which need be solved.

\section{5-2- Innovation}

The most significant innovation recently was the decision to internationalise and integrate the activities of the MVI Solve IT with MVI Proplant, in other words to merge the IT and production technology expertise and to generate new innovation services such as creating new business models for new product or service innovation. It was envisaged that new IT systems should create new opportunities to drive production planning more efficiently and more quickly, by means of digital technologies associated with Industry 4.0, digitisation, Big Data, and virtual reality. Internationalisation was initiated by founding MVI Proplant Bratislava, whilst the merged divisions MVI Solve IT and MVI Proplant were retained in Germany. The German locations focus on resolving the challenges associated with expansion and optimising the traditional business whilst concurrently developing original new service and technical innovations. Therefore, a dual purpose strategy is implemented with the purpose of exploiting existing opportunities with focus on efficiency, whilst pursuing incremental innovation to enhance and strengthens the core business. Concurrently, MVI aims to develop new disruptive innovation products, new business models for new industries.

Company innovation is managed by specific structures and processes, for instance, effective meetings, which allow open exchange of ideas, cross company workshops, sales meetings, attendance at exhibitions and trade fairs, planning and forecasting and training interventions for employees and managers at every organisational level. Employees are rewarded for their contribution to goal achievement by performance-based compensation including commissions. Innovation is optimised by the employees working as outsourced units, rather than at headquarters, on submarine projects, for instance ergonomics, reshaping organisational integration and employee motivation programmes such as exercise and health. The shareholders expect all costs and overhead expenses to be managed so that the firm remains competitive. However, a major challenge for implementing organisational change and an innovative culture in that the German employees have a public sector like culture and are not flexible to change, although the change process is considered complete. The change process is highly planned, slow and restricted by budgets, which deter its development. The knowledge potential is substantial but the office equipment is very old and systems are being renewed slowly. The Managing Directors in Germany make decisions and organise the change.

The level of competition in south Germany means that the pressure to save costs is higher; the higher salary demands increase the price spiral. However, high turnover of staff and middle management has led to inconsistent performance linked to higher cost and lower margins. The Bratislava business has been under construction for three years and remains a virtual start-up company, partly because planning was very conservative, as a consequence of the 
shareholders' fear of failure and loss of image. The small company size means that complexity is low and agility is potentially high, the absence of hierarchies and bureaucracies inhibits self-interest and the internal communication is good, information and ideas are exchanged and a good team spirit exists. Organisational successes are celebrated as a team. However, the development of the business meant that financial resources for training and infrastructure were tightly controlled budgeted. In Bratislava, the employees use the latest systems, which has proven to be a significant big challenge for the employees because they must learn new systems and the associated languages. UMS systems are also used, which ensures modern communication facilities and maintenance contracts have been signed to ensure software upgrades on all technology are implement every year. All employees are able to actively participate in the business and by using the new systems, they should have the environment to generate creativity.

MVI Proplant also participates in open innovation with its clients, for instance its engineers work with clients to develop new products and in the pilot manufacturing of those products using lean production techniques. Incremental innovation is sometimes required because the required tools may not be available so that product adjustments are made at the stage of virtual development. This means that speed to market is not inhibited. MVI engineers also build and test pilot vehicles in conjunction with automotive clients, so that the final production method will deliver the required quality on time.

\section{5-3- Organisational Leadership, Innovation and Change Management}

Two Managing Directors are located in Wolfsburg, one specialising in technology and the other in finance, plus four business unit managers and seven departmental heads. The additional staff at this location are a Human Resources specialist, four managers, one senior manager overseeing all companies, two administrative staff plus four cross company IT administrators and apprentices. In the Munich location, the same two Managing Directors are the key executives but there are three site managers, two Human Resource personnel, one supervisor, and two administrative staff. The staff located in Bratislava comprise one manager, one assistant, one accountant, one employee and financial administrators and a language teacher.

Each location has different processes owing to historical development but innovation is managed by the shareholders and the Managing Directors, and directs change management. The good teamwork and open environment constantly creates new ideas, optimising opportunities for success; all ideas are recorded as tasks and analysed for cost and feasibility. A joint decision is made about; which ideas should be implemented. In general, knowledge is exchanged effectively but language difficulties between the German and Bratislavan locations suggest that improvements are possible and desirable.

The processes are very well organised because the group has worked as a team for a long period and projects are confirmed by the shareholders, but their ideas are very conservative, and decisions are made slowly, hindering the speed of innovation. Hence funds are released too slowly because the motivation to change is low and specialists represent high costs. However, innovation successes are monitored by assessing their contributions to organisational growth.

\section{6- Discussion}

In this section these findings are discussed compared with the key concepts in the Literature Review and those of the empirical studies that were analysed and discussed in the first part of the research into SME Innovation Management, the secondary data contribution.

The company culture is highly traditional, it is hierarchical, risk averse as demonstrated by tight budgeting and the lack of change in the behaviours of the German based employees in recent years; a short term orientation that represents a barrier to change, exemplified by retention of old technology that represents its cultural norms; it has many attributes of large company culture that impedes organisational learning [30]. Whilst the company information implies that change to an innovative culture has already taken place, in fact some of the systems and processes have changed, whilst the culture has not, as Kotter (2012) [28], emphasises, the first stages represent a shift in some behaviours but that does not indicate that cultural values have altered. The organisation is between steps 5 and 6 of the eight-stage plan, as suggested by celebrating successes and system alterations, but German employees retain a public sector attitude. In addition, the Managing Directors are not leading the culture change as they retain inappropriate structures in Germany and high risk attitude that is not appropriate to an innovation culture [28].

The current arrangement that resemble an innovation management attempt to change to an innovation culture include creating the environment for substantial exchange of information and perspectives. The company is striving to accomplish two types of innovation, incremental which is more typical of large companies and original innovation that is more often successful in SMEs. It is also employing considerable external knowledge from its clients when on their premises, which it merges with its current knowledge in order to improve its offering to them, so that both inside out and outside-in open innovation, coupling is a key innovation management approach [49]. 
Amongst the barriers to change not already specified, is the shortage of skills in German which is implied by high staff turnover. Similar conclusions were formulated in Strobel and Kratzer (2017) [50]. However, in contrast to prior findings, this study shows that cooperation ties of firms might also negatively influence the innovative performance.

The total company is not strictly an SME as it has more than 250 employees, but the Bratislava location comes within the definition of a micro or a small enterprise. It currently has the latest technology, a small flexible team and has been provided with training support all of which are innovation management techniques to create an innovation culture. However, serious barriers to innovation are the restricted budgets.

UVI can be described as a paradox at this stage, whilst its business model offered to clients promotes open innovation, its internal organisation generally represents a culture that is hindering innovation. De Massis et al. (2018), Frondel et al. (2008) and Wagner (2008) [51-53] dealt with the innovative environment with an emphasis on German specifics.

\section{7- Recommendations}

The recommendation for the company are provided on the major strengths and weaknesses detected in the case and the major opportunities and threats that were derived eternally from the above cited case studies comprising Chapter Four and Chapter 5, these are summarised in Table 5 and then discussed.

Table 5. Internal Strengths and Weaknesses \& External Opportunities and Threats.

\begin{tabular}{|c|c|}
\hline Strengths & Weaknesses \\
\hline $\begin{array}{l}\text { Bratislava location innovative culture; } \\
\text { Breadth and Depth of External Contacts for Innovative Idea } \\
\text { Creation and Development; } \\
\text { Capacity to practice incremental and original innovation; } \\
\text { Introduction of many opportunities for idea creation and } \\
\text { evaluation. }\end{array}$ & $\begin{array}{l}\text { Retention of traditional culture in German locations; } \\
\text { Bureaucratic structure in Germany; } \\
\text { Lack of leadership for change; } \\
\text { Short term orientation; } \\
\text { Risk averse; } \\
\text { Staff turnover in Germany; } \\
\text { Speed to market of innovation in Bratislava. }\end{array}$ \\
\hline Opportunities & Threats \\
\hline $\begin{array}{l}\text { Develop different innovation management strategy for } \\
\text { Germany and Bratislava; } \\
\text { Increase innovation practices, for instance innovation circles; } \\
\text { Access to new technologies by large firms. }\end{array}$ & $\begin{array}{l}\text { Skills shortages internal and external; } \\
\text { Limited R\&D Planning and Management; } \\
\text { Not getting to market quicker than competitors; } \\
\text { Lack of access to funding. }\end{array}$ \\
\hline
\end{tabular}

The Bratislava Company is effectively a small enterprise, whilst the German operation is a large company, such that their innovation strategies should be devised differently. Innovation management for the German business should resemble that of a large company, which embraces open innovation and incremental change of specific projects for large organisations, which is currently its major income source. In contrast Bratislava would benefit from a flexible approach in which an appropriate strategy would substitute for formal innovation management and drive original product or service innovation. MVI has already introduced interventions for maximising idea generation and evaluation but should add innovation circles, which possibly already exist informally in Bratislava. A longer term approach to financial performance is required if MVI wishes to success in exploiting original innovation in Bratislava and the leadership in Germany must demonstrate visible commitment to change, by changing its behaviours and leading the change of culture. The eight elements of the Korean case culture would be a good model for German location, particularly the HRM tool aspect since existing employee behaviours must be changed to those reflecting an innovative culture, which will need carefully planned interventions and possibly the use of change agents, and recruitment and retention of new staff with requisite skills is an urgent requirement.

\section{8- Conclusion}

The aim of this paper was to develop a broad understanding of innovation management linked to related management literature. In the theoretical framework the related concepts were appraised as relevant to answering the research problem, specifically innovation, innovation management, open innovation and organisational change in the context of developing an organisational innovation culture.

The research problem was to identify the opportunities and challenges for successful innovation management in SMEs. This objective was accomplished in two ways, firstly be selecting a small sample of empirical studies, which evaluated innovation management, innovation culture and organisational change from diverse cultural perspectives and using different innovation management evaluation models, these were presented, analysed and discussed and the 
key success and failure factors identified as well as specific innovation management techniques and the differences between large, medium and small organisations. A new case study was then introduced, a German organisation, which had recently internationalised by creating a new company in Bratislava. Its organisational structure, main activities innovation approaches were identified and its strengths and weaknesses as an innovative company were evaluated. The findings showed that this company, retained a traditional hierarchical culture despite espousing that it practices open innovation and helped its clients to do so. The findings from the above cited cases were then applied to the German company as potential opportunities and threats. This research identified key innovation management success factors for SMES as:

- Innovation management models needed to be adapted to different organisational contexts;

- Culture had a high impact on innovation management focus;

- Social acceptance was a major factor for original new product market success so that customer needs and competitor activities were important information sources;

- Cross cultural and cross functional team working.

The failure factors identified were:

- Skills shortage in the labour market;

- Lack of skills in the company;

- Market uncertainty, imitation by competitors;

- Lack of R\&D planning and management.

The study made three new findings, which add to the current knowledge:

- Innovation circles were an effective innovation management approach to generating and developing ideas and getting innovation to market quickly;

- Government agencies that encourage firms to collaborate effectively enhance the level and success of innovation;

- SMEs and large companies have distinctly different rankings of barriers to innovation and small and micro firms are more effective in original product innovation and speed to market than medium sized companies.

\section{8-1- Limitations}

The limitations of this research are the lack of primary research that was possible. Therefore, recommendations for further include repeating this research but using primary sources of information, a small group of SMEs. The findings would be compared with these secondary outcomes. The surprising finding that micro and small companies were more successful than medium sized companies at new product/service innovation and generating high proportions of their turnover from it, justifies further research into this concept. The validity of the study findings is strong as demonstrated by the convergence of findings with those of the established concepts comprising the Literature Review.

\section{9- Funding}

This work was supported by the IGA VŠDTI č. 007/2019 provided by the DTI University, Dubnica nad Váhom, Slovakia.

\section{0- Conflict of Interest}

The author declares that there is no conflict of interests regarding the publication of this manuscript. In addition, the ethical issues, including plagiarism, informed consent, misconduct, data fabrication and/or falsification, double publication and/or submission, and redundancies have been completely observed by the authors.

\section{1- References}

[1] Reichwald, Ralf and Frank Piller. "Interaktive Wertschöpfung. Open Innovation Individualisierung und neue Formen der Arbeitsteilung. 2nd edition" (2009). doi:10.1007/978-3-8349-9440-0.

[2] Abulrub, Abdul-Hadi G. and Junbae Lee. "Open innovation management: challenges and prospects." Procedia-Social and Behavioral Sciences 41 (2012): 130-138. doi:10.1016/j.sbspro.2012.04.017.

[3] Usman, Muhammad, and Wim Vanhaverbeke. "How start-ups successfully organize and manage open innovation with large companies." European Journal of Innovation Management (2017). doi:10.1108/EJIM-07-2016-0066. 
[4] Brem, Alexander, and Kai-Ingo Voigt. "Integration of market pull and technology push in the corporate front end and innovation management - Insights from the German software industry." Technovation 29 no. 5 (2009): 351-367. doi:10.1016/j.technovation.2008.06.003.

[5] Onwuegbuzie, A and N. Leech. "On Becoming a Pragmatic Researcher: The Importance of Combining Quantitative and Qualitative Research Methodologies.” International Journal of Social Research Methodology 8 no. 5 (2005): $375-387$. doi:10.1080/13645570500402447.

[6] Saunders, Mark, Philip Lewis and Adrian Thornhill. "Research Methods for Business Students. 5th edition” (2018).

[7] Creswell, John W., and David J. Creswell. "Research Design: Qualitative, Quantitative, and Mixed Methods Approaches" (2017).

[8] Naghibi, Mohammad Ali, and Hediyeh Baban. "Strategic change management: The challenges faced by organizations." In international conference on economics and finance research, vol. 4, (2011): 542-544.

[9] Ritchie, Jane and John Lewis. "Qualitative Research Practice.” (2010).

[10] Beer, M. and N. Nohria. “Cracking the code of change.” Harvard Business Review 78, no. 3 (May/June 2000): 133-141.

[11] Stewart, J. and P. Kringas. "Change management - strategy and values. Six case studies from the Australian public sector." Centre for Research in Public Sector Management (2003). doi:10.1111/1540-6210.00331.

[12] Sheil, Christopher. "Globalization: Australian impacts” (2001).

[13] Porras, Jerry, I. and Peter J. Robertson. “Organisational development: Theory, practice, and research.” (1992).

[14] Mintzberg, H. and F. Westley. “Cycles of Organisational Change.” Strategic Management Journal 13 no. 3 (1992): $39-59$. doi:10.1002/smj.4250130905.

[15] Alvesson, Mats, and Stefan Sveningsson. "Changing Organisational Culture. Cultural work in the progress. 2nd edition" (2016). doi:10.4324/9781315688404.

[16] Furr, N. \& J. Dyer. “Leading Your Team into the Unknown.” Harvard Business Review 93 no. 12 (2014): 82-88.

[17] Ambile, T. "Motivating Creativity in Organisations: On Doing What You Love and Loving What You Do." California Management Review 40, no.1 (1997): 39-58. doi:10.2307/41165921.

[18] Kotter, John, P, "Leading Change" (2015).

[19] Lajčin, Daniel, Gabriela Gabrhelová and Ferdinand Korn. "Sociálna a emocionálna inteligencia osobnosti manažéra v priestore morálky a práva $=$ Vybrané osobnostné vlastnosti manažéra v priestore iusnaturalizmu. 1. edition” (2017).

[20] Kanter, Rosabeth Moss. "The change masters: Corporate entrepreneurs at work” (1992).

[21] Lee, S., G. Park, B. Yoon and J. Park. “Open Innovation in SMEs - An Intermediated network model.” Research Policy 39 no. 2 (2010): 290-300.

[22] Lawrence, T.B., B. Dyck, S. Maitlis, and M.K. Mauws. "The underlying structure of continuous change." MIT Sloan Management Review 47 no. 4 (2006): 59-66.

[23] Zimmermann, J. “The principles of managing change.” HR Focus 2 no. 4 (1995): 15-16. doi:10.1108/00438029510082567.

[24] Swedberg, Dan, and Judith Douglas. "Transformation by design: an innovative approach to implementation of e-government." Electronic Journal of E-government 1, no. 1 (2003): 51-56.

[25] Doppler, Klaus, and Christoph Lauterburg. “Change Management. Den Unternehmenswandel gestalten.” (2014).

[26] Cummins, Thomas G. and Christopher G. Worley “Organisation Development and Change. 10th edition” (2015).

[27] Mullins, Laurie, J. “Management and Organisational Behaviour. 9th edition” (2010).

[28] Kotter, John, P. "Leading Change” (2012).

[29] Govindarajan, V. and C. Trimble. “Stop the Innovation Wars.” Harvard Business Review 88 no. 7-8 (2010): 76-83.

[30] Leavy, B. “A leader's guide to creating an innovation culture." Strategy \& Leadership 33 no. 5 (2005): $38-45$. doi:10.1108/10878570510608031.

[31] Currall, S.C., E.B. King, B. Lane, J. Madera and S. Turner. "What drives public acceptance of nanotechnology." Nature Nanotechnology 1, no. 3 (2006): 153-155. doi:10.1038/nnano.2006.155.

[32] Hunter, J. "Is open innovation the way forward in big pharma? Nature Reviews." Drug Discovery 9 no. 2 (2010): 87-88. doi:10.1038/nrd3099. 
[33] Birchall, D.W., J.J. Chanaron and J. Soderquist. "Managing Innovation in SMEs: a comparison of companies in the UK, France and Portugal.” International Journal of Technology Management 12, no. 3 (1996): 291-306.

[34] Rammer, Christian, Dirk Czarnitzki, and Alfred Spielkamp. "Innovation Success of Non-R\&D-Performers: Substituting Technology by Management in SMEs.” Small Business Economics 33, no. 1 (March 26, 2009): 35-58. doi:10.1007/s11187009-9185-7.

[35] Robins, P., and C. O’Gorman. "Innovation Processes: Do They Help of Hinder New Product Development Outcomes in Irish SMEs.” Irish Journal of Management 35 no. 1 (2016): 88-103. doi:10.1515/ijm-2016-0006.

[36] Havlicek, Karel, Eleftherios Thalassinos and Liliana Berezkinova. "Innovation management and controlling in SMEs." (2013). doi:10.35808/ersj/403.

[37] Lendel, Viliam, Štefan Hittmár and Eva Siantová. "Management of innovation processes in company." Procedia economics and finance 23 (2015): 861-866. doi:10.1016/S2212-5671(15)00382-2.

[38] Sulaiman, Rasheed V., Ahmed Hall, Theodore Reddy and Karim Dorai. "Studying rural innovation management: a framework and early findings from Riu in South Asia." (2010).

[39] De Meyer, Arnoud, and Sam Garg. "What makes the implementation of Innovation Management in Asia Different?”. INSEAD working paper 2004/81/ABCM/TM (2004). doi:10.1057/9780230512061_6.

[40] Moore, Geoffrey A. "Darwin and the demon: Innovating within established enterprises." Harvard business review 82, no. 7-8 (2004): 86-92.

[41] Suija-Markova, Inese, Liene Briede, Elīna Gaile-Sarkane, and Iveta Ozolina-Ozola. "Multitasking in Knowledge Intensive Business Services.” Emerging Science Journal 4, no. 4 (August 1, 2020): 305-318. doi:10.28991/esj-2020-01233.

[42] Franken, Rolf and Swetlana Franken, S. "Integriertes Wissens- und Innovationsmanagement” (2011). doi:10.1007/978-3-83496724-4.

[43] Davenport, Thomas, H. "Process Innovation: reengineering work through information technology. (1992).

[44] Levitt, Theodore. "Innovation in marketing: new perspectives for profit and growth" (1962).

[45] Hartschen, Michael, Jiri Scherer, and Chris Brügger. "Innovation Management: Die 6 Phasen von der Idee zur Umsetzung. 3rd edition" (2009).

[46] Dyer, J.H. and H. Singh. "The relational view: Cooperative strategy and sources of inter-organisational competitive advantage." Academy of Management Review 23 no. 4 (1998): 660-679. doi:10.5465/amr.1998.1255632.

[47] Kotter, John, P. "Leading Change” (1996).

[48] Gassmann, Oliver, and Ellen Enkel. "Towards a theory of Open Innovation: Three Core Process Archetypes" (2004).

[49] Lycke, L. "Team development when implementing TPM." Total Quality Management 14 no. 2 (2003): $205-213$. doi:10.1080/1478336032000051395.

[50] Strobel, Natalia and Jan Kratzer. "Obstacles to innovation for SMEs: Evidence from Germany." International Journal of Innovation Management 21 no. 03 (2017): 1750030. doi:10.1142/S136391961750030X.

[51] De Massis, Alfredo, David Audretsch, Lorraine Uhlaner and Nadine Kammerlander. "Innovation with Limited Resources: Management Lessons from the German Mittelstand." Journal of Product Innovation Management 35 no. 1 (2018): 125-146. doi:10.1111/jpim.12373.

[52] Frondel, Manuel, Jens Horbach and Klaus Rennings. "What triggers environmental management and innovation? Empirical evidence for Germany." Ecological Economics 66 no. 1 (2008): 153-160. doi:10.1016/j.ecolecon.2007.08.016.

[53] Wagner, Stephan M. "Innovation management in the German transportation industry." Journal of Business Logistics 29 no. 2 (2008): 215-231. doi:10.1002/j.2158-1592.2008.tb00093.x. 